\title{
The effects of creatine and glycerol hyperhydration on running economy in well trained endurance runners
}

\author{
Lukas Y Beis ${ }^{1}$, Thelma Polyviou', Dalia Malkova ${ }^{2}$ and Yannis P Pitsiladis ${ }^{1 *}$
}

\begin{abstract}
Background: Ingestion of creatine ( $\mathrm{Cr}$ ) and glycerol (Gly) has been reported to be an effective method in expanding water compartments within the human body, attenuating the rise in heart rate (HR) and core temperature $\left(T_{\text {core }}\right)$ during exercise in the heat. Despite these positive effects, a substantial water retention could potentially impair endurance performance through increasing body mass (BM) and consequently impacting negatively on running economy (RE). The objective of the present study was to investigate the effects of a combined $\mathrm{Cr}$ and Gly supplementation on thermoregulatory and cardiovascular responses and RE during running for $30 \mathrm{~min}$ at speed corresponding to $60 \%$ of maximal oxygen uptake $\left(\mathrm{V}_{2}\right.$ max) in hot and cool conditions.

Methods: $\mathrm{Cr} \cdot \mathrm{H}_{2} \mathrm{O}(11.4 \mathrm{~g})$, Gly $\left(1 \mathrm{~g} \cdot \mathrm{kg}^{-1} \mathrm{BM}\right)$ and Glucose polymer $(75 \mathrm{~g})$ were administered twice daily to 15 male endurance runners during a 7-day period. Exercise trials were conducted pre- and post-supplementation at 10 and $35^{\circ} \mathrm{C}$ and $70 \%$ relative humidity.

Results: $\mathrm{BM}$ and total body water increased by $0.90 \pm 0.40 \mathrm{~kg}(P<0.01$; mean $\pm \mathrm{SD})$ and $0.71 \pm 0.42 \mathrm{~L}(P<0.01)$, respectively following supplementation. Despite the significant increase in $\mathrm{BM}$, supplementation had no effect on $\dot{\mathrm{V}} \mathrm{O}_{2}$ and therefore RE. Both HR and $\mathrm{T}_{\text {core }}$ were attenuated significantly after supplementation $(P<0.05$, for both). Nevertheless, thermal comfort and rating of perceived exertion was not significantly different between pre- and post-supplementation. Similarly, no significant differences were found in sweat loss, serum osmolality, blood lactate and in plasma volume changes between pre- and post-supplementation.
\end{abstract}

Conclusions: Combining $\mathrm{Cr}$ and Gly is effective in reducing thermal and cardiovascular strain during exercise in the heat without negatively impacting on RE.

\section{Background}

Running economy (RE), which is defined as the submaximal oxygen consumption $\left(\mathrm{V}_{2}\right)$ at a given running velocity, is an important physiological parameter as superior RE is essential for successful endurance running performance $[1,2]$. In general, runners with good $\mathrm{RE}$ use less oxygen than runners with poor RE at the same absolute exercise intensity. RE appears to be influenced by many physiological factors [1] including hydration status. Coyle (2003) proposed that a -4 to $-8 \%$ body mass (BM) deficit due to dehydration (i.e., the process

\footnotetext{
* Correspondence: Yannis.Pitsiladis@glasgow.ac.uk

${ }^{1}$ College of Medicine, Veterinary and Life Sciences, Institute of Cardiovascular and Medical Sciences, University of Glasgow, Glasgow, UK

Full list of author information is available at the end of the article
}

of reducing body water) may lower the oxygen cost of movement [3], given that athletes who lose the most BM during a race are usually the most successful [4]. Nevertheless, this theoretical paradigm contradicts the prevailing view of a body water deficit in excess of $2-3 \%$ BM constituting the level of dehydration that can adversely affect performance [5].

During exercise, skeletal muscle produces a significant amount of heat. When this metabolic heat production exceeds total heat loss, core body temperature $\left(\mathrm{T}_{\text {core }}\right)$ rises. Consequently, endurance exercise performance in hot and dry environments can be limited by the increase in $\mathrm{T}_{\text {core }}$ [6]. An increase in $\mathrm{T}_{\text {core }}$ during can be attenuated via the secretion and evaporation of sweat through the skin with inevitable body water loss. This decrease in body water is hypothesized to decrease plasma

\section{C) Biomed Central}


volume (PV) and consequently reduce the sweating response and therefore thermoregulation capacity, increase heart rate (HR) and reduce skin blood flow [7]. Improved maintenance of $\mathrm{PV}$ is the overriding rationale for fluid ingestion during exercise by those supportive of the "cardiovascular model of dehydration" [5]. However, proposed guidelines [5] are not always practical (e.g., difficulties providing adequate drinks during a race, athletes difficulties in drinking while running) and athletes typically refrain from consuming recommended amounts of fluids. Other means to expand PV can be by infusion of isotonic saline [8] with somewhat conflicting success $[8,9]$. More recent approaches aimed at expanding body water compartments using hydrating agents such as creatine $(\mathrm{Cr})$ and glycerol (Gly) have successfully attenuated the rise in $\mathrm{T}_{\text {core }}$ and $\mathrm{HR}$ during exercise in heat $[10,11]$.

Cr has been shown to have hydrating effects $[12,13]$, although the exact process has yet to be established. Ingestion of $20 \mathrm{~g} \cdot \mathrm{d}^{-1}$ of $\mathrm{Cr}$ dissolved in $500 \mathrm{~mL}$ of water for 7 days have proved successful in attenuating the rise in $\mathrm{HR}$ and $\mathrm{T}_{\text {core }}$ during exercise in the heat [13]. These effects have been attributed to an increase in intracellular water (ICW), resulting in an increased specific heat capacity of the body $[12,13]$. Moreover, whole body $\mathrm{Cr}$ retention is $60 \%$ higher when consumed with carbohydrate $(\mathrm{CHO})$ compared to when $\mathrm{Cr}$ was consumed alone [14]. Although the mechanism by which $\mathrm{CHO}$ enhances $\mathrm{Cr}$ uptake is not completely understood, consumption of $100 \mathrm{~g}$ per $5 \mathrm{~g}$ of $\mathrm{Cr}$ has been recommended for the effective improvement of Cr uptake [15]. Like $\mathrm{Cr}$, Gly has been found to be an effective agent in expanding the water compartments within the human body $[11,16]$. Gly, seems to expand the ICW as well as the extracellular water (ECW) [17]. In general, doses of 1.0-1.5 g Gly. $\mathrm{kg}^{-1}$ BM dissolved in 1.4 - $2.0 \mathrm{~L}$ of fluid $2.5-4 \mathrm{~h}$ before exercise [18] increase total body water (TBW) compartments and reduce thermal and cardiovascular strain during exercise in the heat.

Supplementation with combined hydrating agents such as Gly or $\mathrm{Cr}$ has consistently produced modest fluid retention of $400-800 \mathrm{~mL}$ [10-12]. Easton et al. (2007) were the first to add Gly to a Cr containing solution and demonstrate that a combination of the two hyperhydrating agents has an additive effect, as the addition of Gly to $\mathrm{Cr}$ significantly increased TBW more than $\mathrm{Cr}$ alone. Although the combination of the aforementioned hyperhydrating agents results in an increase in TBW and a reduction in certain cardiovascular and thermoregulatory responses [19], the BM increase due to enhanced hydration status could potentially reduce RE. The reduction of the energy cost of movement at a sub-maximal velocity by way of reducing BM to improve running performance is well known [20]. For instance, it is noted that some marathon runners perform well despite dehydration of 4-8\% BM [21]. Coyle [3] proposed that this may occur because fluid loss (i.e., reduced body mass) lowers the oxygen cost of movement. On the other hand, the acute influences of hyperhydration on RE has not been investigation to date. Hence, the aim of the present study was to investigate the effects of hyperhydration induced by a combined $\mathrm{Cr}$ and Gly supplementation on thermoregulatory and cardiovascular responses and RE during $30 \mathrm{~min}$ of running at a running speed corresponding to $60 \% \dot{\mathrm{VO}}_{2}$ max in cool $\left(10^{\circ} \mathrm{C}\right.$ with a relative humidity of $\left.70 \%\right)$ and hot conditions $\left(35^{\circ} \mathrm{C}\right.$ with a relative humidity of $\left.70 \%\right)$ in well trained male athletes. In cool ambient conditions were intended to minimize heat stress during exercise this enabling a focus on the effects of the altered $\mathrm{BM}$ induced by hyperhydration on $\mathrm{RE}$ at $60 \% \dot{\mathrm{VO}}_{2}$ max. However, effects of hyperhydration on thermoregulatory and cardiovascular responses are also expected during exercise in hot and humid conditions; conditions typical of major sporting events (e.g., Olympic Summer Games). As such, it was hypothesized that an increase in BM and TBW induced by hydrating agents such as Gly or Cr would improve thermoregulatory and cardiovascular responses in line with previous findings but potentially negatively influence $\mathrm{RE}$ during running in the heat.

\section{Methods}

\section{Subjects}

Fifteen trained male runners gave their written informed consent to take part in the present study which was approved by the University of Glasgow Ethics Committee and was performed according to the code of ethics of the World Medical Association (Declaration of Helsinki). One subject withdrew from the study before the final trial because of gastrointestinal distress during supplementation. Subjects were questioned as to their supplementation and training practices in order to ascertain that they had not supplemented with $\mathrm{Cr}$ for at least 8 weeks prior to commencing the study. Subjects were in good health at the time of testing, ran on a daily basis and participated regularly in competitive races. Athletes were also requested to maintain their typical weekly training regime during the course of the study.

\section{Study design: Preliminary exercise tests}

All subjects completed a $\dot{\mathrm{V}}_{2}$ max test during an initial continuous incremental test at standard room temperature $\left(20-21^{\circ} \mathrm{C}\right)$ and relative humidity $(30-40 \%)$ on a motorized treadmill (PPS Med, Woodway, Germany) at $1 \%$ grade. After a warm-up period (depending on the runner), the subjects started running at $8 \mathrm{~km} \cdot \mathrm{h}^{-1}$ for 3 
min in order to reach a steady state. In the next exercise bout the treadmill speed was set to $10 \mathrm{~km} \cdot \mathrm{h}^{-1}$ for $3 \mathrm{~min}$ and this procedure was repeated with $2 \mathrm{~km} \cdot \mathrm{h}^{-1}$ increments in running speed until volitional exhaustion of the subject. During the test expired gas samples (30 s collection time at the end of each bout) were taken using Douglas bag collection technique as is considered the gold standard method [22] and analyzed for $\mathrm{O}_{2} \%$ and $\mathrm{CO}_{2} \%$ (Servopro 4100 Gas Purity Analyzer, Servomex, UK) as well as analyzed for volume using a dry gas meter (Harvard, Kent, UK) and temperature of expired gases. Barometric pressure was measured using a standard mercury barometer. Additionally, a HR monitor (Polar Sports Tester, Polar Electro Oy, Kempele, Finland) was attached prior to each test and HR was recorded at the end of each bout. The $\dot{\mathrm{VO}}_{2}$ max measurement was used for calculating the intensity (60\% of $\dot{\mathrm{VO}}_{2}$ max) that subjects would perform during the actual tests. Running speed at $60 \%$ of $\mathrm{VO}_{2}$ max (exercise intensity) was calculated using the linear relation between treadmill speed and $\dot{\mathrm{V}} \mathrm{O}_{2}$.

Prior to the actual experimental trials, familiarization trials were completed until the variability of $\dot{\mathrm{VO}}_{2}$ of two consecutive trials was within $5 \%$ difference. No subject had to complete a third familiarization trial to achieve less than $5 \%$ variability, an observation which is in line with our previous experience of trained runners [23]. At least three days after this familiarization period, subjects reported to the laboratory for the first experimental trial (i.e., a pre-supplementation trial). After this baseline test, all subjects commenced the hyperhydration treatment comprising Cr, Gly and Glu. For this, subjects consumed a solution of $11.4 \mathrm{~g}$ of $\mathrm{Cr} \cdot \mathrm{H}_{2} \mathrm{O}$ (equivalent to 10 g Cr), (Reflex Creapure Creatine, Reflex Nutrition LTD, UK), $1 \mathrm{~g} \cdot \mathrm{kg}^{-1}$ of BM Gly (Glycerin BP/Value Health Glycerin BP, Boots Company plc) and $75 \mathrm{~g}$ of Glu polymer ( $\mathrm{SiS}$ GO electrolyte), mixed in hot water (approximately $50^{\circ} \mathrm{C}$ ) and made up in $1 \mathrm{~L}$ of cold water twice daily. This supplementation regimen was followed for 6 days. This protocol has been shown to increase resting muscle-phosphocreatine levels within 5 days [24]. On the day of the post-supplementation test (i.e., day $7^{\text {th }}$ ) subjects began consuming the final supplement $5 \mathrm{~h}$ before the exercise-performance trial (with instructions to complete ingestion within $1 \mathrm{~h}$ ). Hypertonic solutions such as the Cr, Gly, Glu combination ( 1556 $\mathrm{mOsm} \cdot \mathrm{kg}^{-1}$ ) cause an initial net secretion of water into the intestinal lumen [25], resulting in an effective loss of body water, albeit temporary. Unpublished work from our laboratory has indicated that ingesting $\mathrm{Cr} / \mathrm{Gly} 5 \mathrm{~h}$ prior to commencement of exercise results in a larger volume of fluid absorbed compared to when the solution is consumed $3 \mathrm{~h}$ prior to the exercise test. In order to prevent degradation of $\mathrm{Cr}$ to creatinine, each supplement was prepared fresh each time before consumption. The subject was also given a temperature pill (HQ Inc., USA) about 8-12 h prior to each test allowing $\mathrm{T}_{\text {core }}$ to be measured [26]. On each of the experimental test days, subjects ingested $500 \mathrm{~mL}$ of water $1 \mathrm{~h}$ before exercise in an attempt to ensure euhydration before all exercise trials [27] (Figure 1). Subjects otherwise followed their normal diet and recorded all food and drink consumed during the supplementation period as well as the preceding week using a food diary. The diet was analyzed for energy intake and macronutrient content using computerized food-composition tables [28] (Food Meter U.K., Medimatica s.r.l., Benedetto, Italy). Subjects were asked to minimize caffeine intake to 1 cup of tea or coffee per day to lessen any possible confounding effects of caffeine on $\mathrm{Cr}$ [29].

\section{Experimental Procedures}

The subject reported to the lab after a $3 \mathrm{~h}$ fast and having refrained from alcohol, caffeine, and strenuous exercise at least $24 \mathrm{~h}$ prior to the experimental trial. Firstly, a urine sample was collected from the subject prior to taking the pre-test nude BM (Tanita Corporation of America, Inc.). Body water compartments were estimated using a multi frequency bioimpedance analyzer (Quadscan 4000, Bodystat Ltd., Isle of Man) while the subject lay comfortably in a supine position for $5 \mathrm{~min}$ on a nonconductive surface with their arms and legs slightly abducted. This method allows TBW and ECW to be estimated. From these measurements ICW can also be deduced. Bioimpedance has been shown to produce valid and reliable TBW estimations in the euhydrated state [30]. To date, several studies have successfully used this technique in order to estimate hyperhydration induced changes in TBW $[12,13]$. Changes in BM from pre- to post-supplementation were used to supplement the indirect measurement of the fluid volume retained. Following TBW determination, the subject lay in a supine position for $5 \mathrm{~min}$ further and a $7 \mathrm{~mL}$ blood sample was taken from a $21 \mathrm{G}$ cannula which was introduced into a superficial vein of the anticubital fossa of the right arm. The venous cannula was kept patent by flushing it with $7 \mathrm{~mL}$ of isotonic saline solution between samples. Prior entering the environmental chamber a HR monitor (Polar Sports Tester, Polar Electro Oy, Kempele, Finland) was attached to the subject. Then, the subject was transferred to the climatic chamber (ambient temperature 10.0 $\pm 1.0^{\circ} \mathrm{C}$ with a relative humidity of $68.5 \pm 3.6 \%$. Subjects were then instructed to begin running to their predetermined $60 \% \dot{\mathrm{VO}}_{2}$ max for $30 \mathrm{~min}$ at $1 \%$ inclination of the treadmill. $\mathrm{HR}$ and $\mathrm{T}_{\text {core }}$ were recorded every $5 \mathrm{~min}$ throughout the 30-min exercise period. 1 min gas 


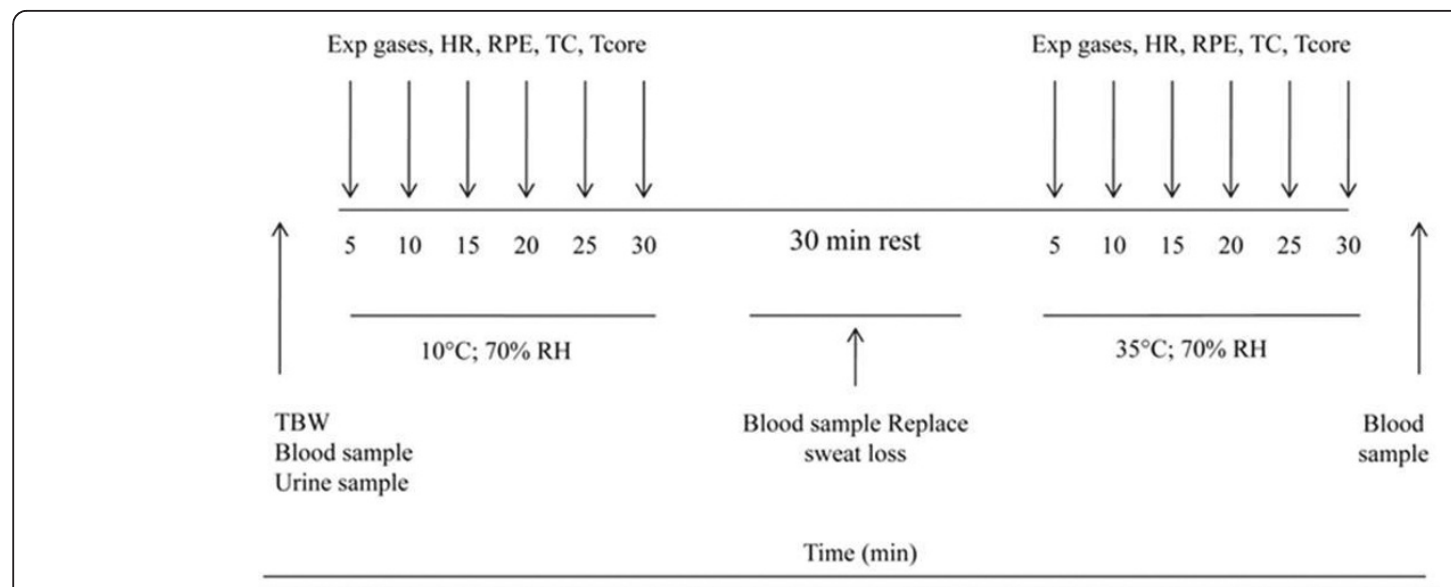

Figure 1 Schematic representation of the experimental protocol.

measurements were collected at 5 min intervals of exercise for the purpose of $\dot{\mathrm{V}}_{2}$, carbon-dioxide production $\left(\dot{\mathrm{V}} \mathrm{CO}_{2}\right)$, temperature and expired gas volume determination. Rating of perceived exertion (RPE; Figure 2) and thermal comfort (TC; Figure 3) were recorded every $5 \mathrm{~min}$ of the exercise using the Borg category scale [31] for RPE and a modified scale (from -10 to +10 ). Following the first exercise bout, the subject was removed from the chamber and nude BM was measured immediately. The difference in BM before and after exercise was calculated and subsequently used to estimate sweat loss. Subsequent to BM determination, the subject lay in a supine position for 10 min and a final blood sample was retrieved. The fluid loss was then replaced by giving the subject the equivalent amount of water to that calculated between pre- and postexercise. Subjects were then instructed to re-enter the climatic chamber and complete a second bout of run at the same speed $\left(60 \% \dot{\mathrm{V}} \mathrm{O}_{2} \max \right)$, at $35.1 \pm 0.1^{\circ} \mathrm{C}$ and $69.4 \pm$ $4.0 \%$ relative humidity. The protocol for data collection was identical to the one used in the first bout of exercise. Once the second bout was completed, subjects' nude BM

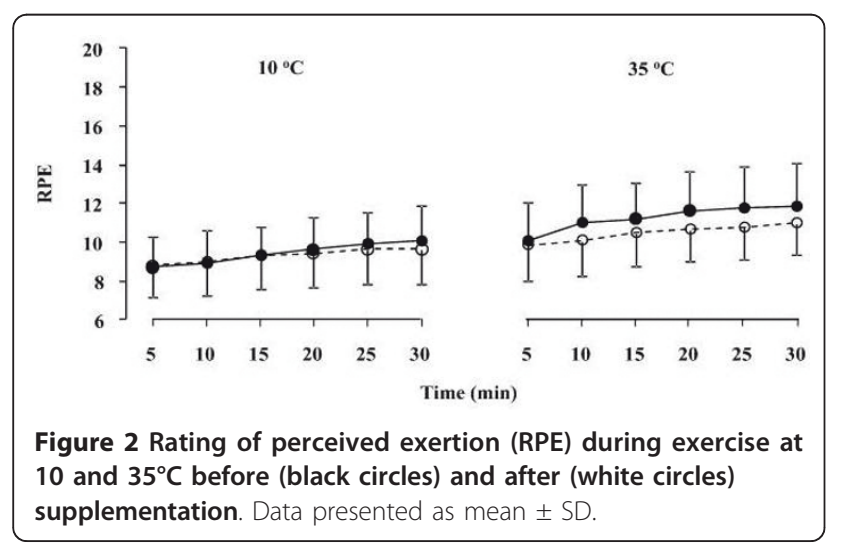

and a final blood sample were taken as described above. The analytical procedure is shown in Figure 1.

Blood was drawn into dry syringes and $4 \mathrm{~mL}$ dispensed into a tube containing $\mathrm{K}_{3}$ EDTA and the remaining $3 \mathrm{~mL}$ dispensed into plain tubes. Duplicate aliquots $(100 \mu \mathrm{L})$ of whole blood from the $\mathrm{K}_{3}$ EDTA tube were rapidly deproteinized in $1000 \mu \mathrm{L}$ of ice-cold $0.3-\mathrm{mmol} / \mathrm{L}$ perchloric acid, centrifuged (8 min, $14000 \mathrm{rpm}$, HettichMicrocentrifuge, Germany), and frozen for later analysis of lactate using a standard enzymatic method [32] involving fluorimetric detection (Spectramax M2 Microplate Reader, Molecular Devices, Inc., US). The blood in tubes without anticoagulant was allowed to coagulate and then centrifuged; the serum collected was used to measure osmolality by freezing-point depression (Microosmometer 3300, Vitech Scientific, West Sussex, UK). The blood from the $K_{3}$ EDTA tubes was also analyzed for hemoglobin (cyanmethemoglobin method) and packed-cell volume (conventional microhematocrit method). All blood analyses were carried out in duplicate, with the exception of packed-cell volume, which was carried out in triplicate. PV changes were calculated from changes in hemoglobin and packed-cell volume relative to initial baseline values [33].

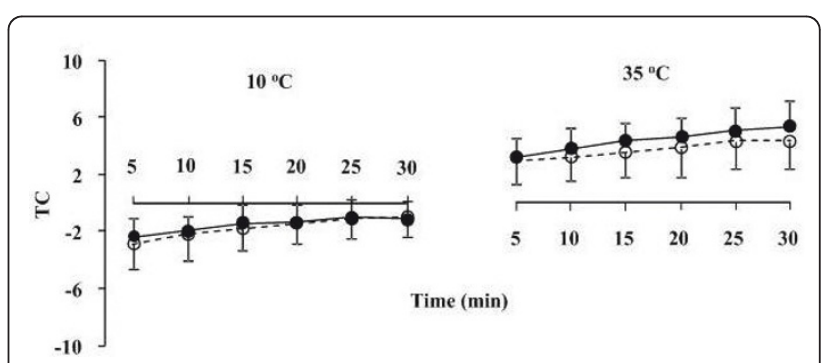

Figure 3 Thermal comfort (TC) during exercise at 10 and $35^{\circ} \mathrm{C}$ before (black circles) and after (white circles) supplementation. Data presented as mean \pm SD. 


\section{Statistical analysis}

All data are expressed as the mean \pm SD. All experimental variables $\left(\dot{\mathrm{VO}}_{2}, \dot{\mathrm{V}} \mathrm{CO}_{2}, \mathrm{RER}, \mathrm{RPE}, \mathrm{TC}, \mathrm{HR}\right.$, $\mathrm{T}_{\text {core }}$ ) were tested for normality of distribution and compared between the two treatments using a repeated measures two-way analysis of variance (ANOVA) (i.e., pre- vs. post-supplementation). Students paired t-tests were carried out to test difference between each time pre- to post-supplementation when difference was detected using ANOVA. Statistical significance was set at $P<0.05$ and in cases where significant differences were detected between time points pre- to post-supplementation, $P$-value was corrected using the Sidak adjustment. Responses at 10 and $35^{\circ} \mathrm{C}$ were analysed separately. Student paired t-tests were also used to examine the difference between pre- to post-supplementation for the rest of the comparisons. All statistical analysis was completed using the statistical package SPSS, version 15.0 (Statistica 8.0, Statsoft Inc., Tulsa, USA).

\section{Results}

\section{Subject characteristics}

The 15 male subjects were trained distance runners with $\dot{\mathrm{VO}}{ }_{2}$ max being $63.5 \pm 5.2 \mathrm{ml} \cdot \mathrm{kg}^{-1} \cdot \mathrm{min}^{-1}$, age, $24 \pm 5 \mathrm{yr}$; height, $180 \pm 7 \mathrm{~cm}$; BM, $69.5 \pm 5.0 \mathrm{~kg}$ (values are presented as the mean \pm SD).

\section{Body Mass and Water Compartments}

Supplementation induced significant increase in BM, TBW, ICW and ECW $(P<0.01$; Figure 4$)$. During supplementation period as well as the preceding week averaged daily energy intake (Pre: $12.8 \pm 2.1 \mathrm{MJ} \cdot \mathrm{d}^{-1}$;
Post: $11,5 \pm 2.4 \mathrm{M} \mathrm{J} \cdot \mathrm{d}^{-1}$ ) and averaged proportion of energy obtained from carbohydrate (Pre: $55 \pm 5 \%$; Post: $49 \pm 11 \%$ ), fat (Pre: $33 \pm 5 \%$ Post: $36 \pm 6 \%$ ), and protein (Pre: $13 \pm 1 \%$; Post: $14 \pm 3 \%$ ) were not significant different.

\section{Cardiopulmonary Variables}

Over the duration of running at $10^{\circ} \mathrm{C} \dot{\mathrm{VO}_{2}}, \dot{\mathrm{V}} \mathrm{CO}_{2}$ and respiratory exchange ratio (RER) remained constant (Table 1). Over the duration of running at $35^{\circ} \mathrm{C} \dot{\mathrm{VO}}_{2}$ and $\dot{\mathrm{V} C O}{ }_{2}$ increased significantly $(P<0.05$, AVOVA, time effect) while the values of RER were constant. No significant differences were detected for $\dot{\mathrm{VO}}_{2}, \dot{\mathrm{VCO}}_{2}$, RER between pre- and post-supplementation trials during running at both 10 and $35^{\circ} \mathrm{C}$ (Table 1 ). HR increased significantly over the duration of running at 10 and $35^{\circ} \mathrm{C}(P<0.05$, for both, ANOVA, time effect). During running at $10^{\circ} \mathrm{C}$ there was no difference in $\mathrm{HR}$ between pre-and post-supplementation trials (Figure 5). During running at $35^{\circ} \mathrm{C}, \mathrm{HR}$ was significantly lower $(P<0.05$, ANOVA, trial effect $)$ in the post-supplementation trial compared to the pre-supplementation trial.

\section{Rating of Perceived Exertion (RPE) and Thermal Comfort} (TC)

Over the duration of running conducted at both 10 and $35^{\circ} \mathrm{C}$ significant $(P<0.05$, ANOVA, time effect) increases were detected in RPE (Figure 2) and TC (Figure 3), while no significant differences were found between pre- and post-supplementation trials.

\section{Change in parameter}

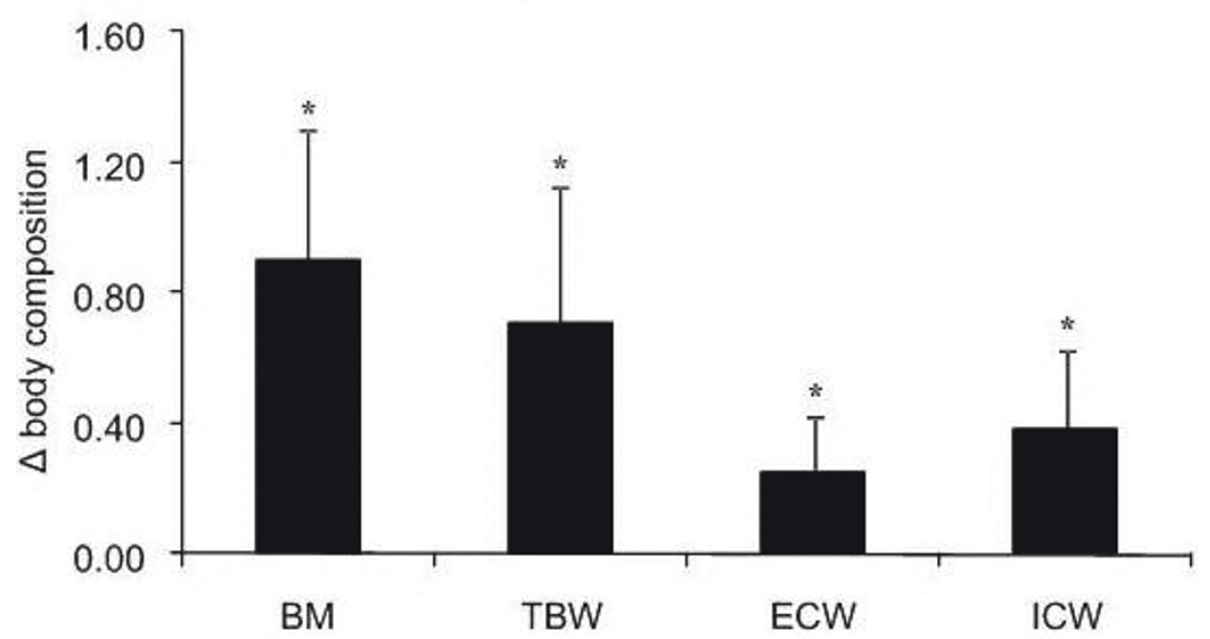

Figure 4 Changes in body mass (BM), total body water (TBW), extracellular water (ECW) and intracellular water (ICW) induced by supplementation. Data presented as mean \pm SD. *Significant difference between pre- and post-supplementation. The units for $\Delta$ body composition are $\mathrm{kg}$ for $\mathrm{BM}$ and $\mathrm{L}$ for body water compartments. 
Table 1 Oxygen consumption $\left(\dot{\mathrm{V}}_{2}\right)$, carbon dioxide production $\left(\dot{\mathrm{V} C \mathrm{O}_{2}}\right)$, respiratory exchange ratio (RPE) during 30 min of running at 10 and $35^{\circ} \mathrm{C}$ conducted before and after supplementation.

\begin{tabular}{|c|c|c|c|c|c|c|c|c|}
\hline \multirow[b]{2}{*}{ Variable } & \multirow[b]{2}{*}{ Condition } & & \multicolumn{6}{|c|}{ Exercise time $(\mathrm{min})$} \\
\hline & & & 5 & 10 & 15 & 20 & 25 & 30 \\
\hline \multirow{4}{*}{$\underset{\left(\mathrm{VL} \cdot \mathrm{kg}^{-1} \cdot \mathrm{min}^{-1}\right)}{\dot{m}}$} & $10^{\circ} \mathrm{C}$ & Pre & $37.4 \pm 2.4$ & $37.6 \pm 2.0$ & $37.7 \pm 1.8$ & $38.7 \pm 2.2$ & $38.8 \pm 2.7$ & $38.9 \pm 2.8$ \\
\hline & & Post & $36.4 \pm 2.8$ & $37.4 \pm 1.5$ & $36.9 \pm 1.7$ & $37.7 \pm 1.8$ & $37.6 \pm 2.2$ & $38.4 \pm 3.3$ \\
\hline & $35^{\circ} \mathrm{C}$ & Pre $^{a}$ & $37.2 \pm 2.4$ & $39.5 \pm 2.4$ & $39.5 \pm 2.3$ & $40.3 \pm 2.6$ & $40.5 \pm 4.4$ & $41.2 \pm 3.3$ \\
\hline & & Post $^{\mathrm{a}}$ & $36.7 \pm 2.4$ & $37.9 \pm 2.3$ & $37.4 \pm 3.2$ & $38.4 \pm 2.6$ & $39.1 \pm 2.1$ & $38.5 \pm 3.1$ \\
\hline \multirow{4}{*}{$\underset{\left(\mathrm{mL} \cdot \mathrm{kg}^{-1} \cdot \mathrm{min}^{-1}\right)}{\dot{\mathrm{C}}}$} & $10^{\circ} \mathrm{C}$ & Pre $^{a}$ & $32.8 \pm 1.7$ & $33.7 \pm 2.2$ & $33.9 \pm 1.4$ & $34.4 \pm 2.0$ & $34.7 \pm 2.5$ & $34.4 \pm 2.5$ \\
\hline & & Post $^{a}$ & $33.5 \pm 3.1$ & $34.6 \pm 1.6$ & $34.0 \pm 1.7$ & $35.0 \pm 1.9$ & $35.1 \pm 2.0$ & $35.0 \pm 2.3$ \\
\hline & $35^{\circ} \mathrm{C}$ & Pre & $32.3 \pm 2.8$ & $34.7 \pm 2.3$ & $35.6 \pm 2.3$ & $35.3 \pm 2.2$ & $35.5 \pm 3.2$ & $35.5 \pm 3.3$ \\
\hline & & Post & $32.4 \pm 2.5$ & $33.9 \pm 2.2$ & $34.4 \pm 2.4$ & $35.1 \pm 2.3$ & $35.1 \pm 2.3$ & $34.5 \pm 2.6$ \\
\hline \multirow[t]{4}{*}{ RER } & $10^{\circ} \mathrm{C}$ & Pre & $0.87 \pm 0.03$ & $0.89 \pm 0.03$ & $0.89 \pm 0.03$ & $0.88 \pm 0.04$ & $0.89 \pm 0.04$ & $0.88 \pm 0.03$ \\
\hline & & Post & $0.91 \pm 0.05$ & $0.93 \pm 0.03$ & $0.92 \pm 0.03$ & $0.93 \pm 0.03$ & $0.93 \pm 0.03$ & $0.92 \pm 0.03$ \\
\hline & $35^{\circ} \mathrm{C}$ & Pre & $0.87 \pm 0.05$ & $0.88 \pm 0.03$ & $0.89 \pm 0.03$ & $0.88 \pm 0.04$ & $0.88 \pm 0.05$ & $0.86 \pm 0.05$ \\
\hline & & Post & $0.88 \pm 0.03$ & $0.89 \pm 0.03$ & $0.91 \pm 0.03$ & $0.91 \pm 0.03$ & $0.90 \pm 0.03$ & $0.89 \pm 0.03$ \\
\hline
\end{tabular}

${ }^{*}$ Note. Values are presented as the mean $\pm \mathrm{SD}$. ${ }^{a}$ Significant difference over time throughout the trial. $P$-value was set at 0.05 .

\section{Core Temperature}

Over the duration of running conducted at both 10 and $35^{\circ} \mathrm{C} \mathrm{T}_{\text {core }}$ increased significantly $(P<0.05$, for both, ANOVA, time effect) (Figure 6). During running at $35^{\circ} \mathrm{C}$ $\mathrm{T}_{\text {core }}$ was significantly lower $(P<0.01$, ANOVA, trial effect) in post- than pre- supplementation trial. During running at $10^{\circ} \mathrm{C}$ there was no difference in $\mathrm{T}_{\text {core }}$ between pre- and post-supplementation trials.

\section{Urine osmolality}

No significant changes were found in urine osmolality between the pre- $\left(438 \pm 306 \mathrm{mOsm} \cdot \mathrm{kg}^{-1}\right)$ and post-supplementation trials $\left(448 \pm 266 \mathrm{mOsm} \cdot \mathrm{kg}^{-1}\right)$.

\section{Total Sweat Loss}

During running at $10^{\circ} \mathrm{C}$ no significant differences between pre- and post-supplementation trials were observed in sweat loss (Pre: $0.3 \pm 0.1 \mathrm{~L}$; Post: $0.3 \pm 0.1$

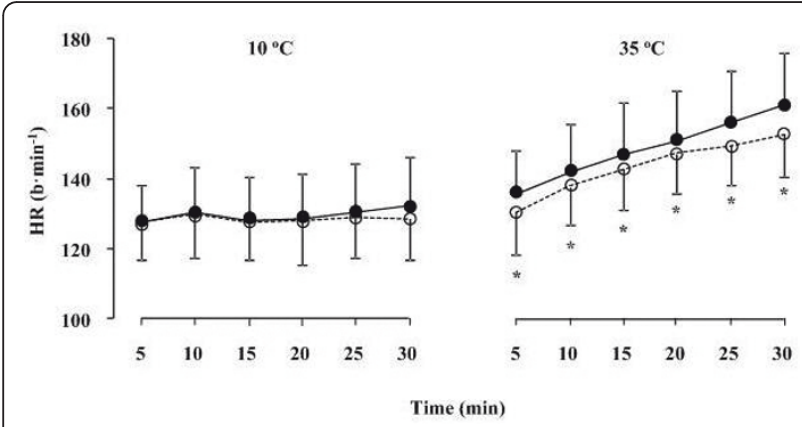

Figure 5 Heart rate (HR) during exercise at 10 and $35^{\circ} \mathrm{C}$ before (black circles) and after (white circles) supplementation. Data presented as mean \pm SD. *Significant difference between pre- and post-supplementation.
L). Similarly, during running at $35^{\circ} \mathrm{C}$ no significant differences between pre- and post-supplementation trials were observed in sweat loss (Pre: $0.7 \pm 0.2 \mathrm{~L}$; Post: $0.8 \pm$ $0.2 \mathrm{~L})$.

\section{Blood Lactate and Plasma Volume}

During running at both 10 and $35^{\circ} \mathrm{C}$ no significant differences were found between pre- and post-supplementation trials in resting concentration of blood lactate. Furthermore, no significant increase in blood lactate was observed over duration of exercise. Additionally, during running at both 10 and $35^{\circ} \mathrm{C}$ no significant differences were detected between pre- and post-supplementation trials in PV changes.

\section{Osmolality}

Resting serum osmolality did not differ between pre$\left(268 \pm 9 \mathrm{mOsm} \cdot \mathrm{kg}^{-1}\right)$ and post-supplementation $(271 \pm$ $19 \mathrm{mOsm} \cdot \mathrm{kg}^{-1}$ ) trials. Additionally, no differences were observed between the post 10 and $35^{\circ} \mathrm{C}$ bouts and the resting values or between the treatments.

\section{Side Effects}

In general, subjects tolerated the supplementation protocol well, with only 1 report of gastrointestinal distress after supplementation who withdrew from the experimental process before completing the post-supplementation trial. This report is in line with the previous study by Easton et al. (2007), where 1 athlete had to also withdraw from the study due to similar reasons.

\section{Discussion}

The novel finding of this study is that a previously established pre-exercise water loading strategy using a 


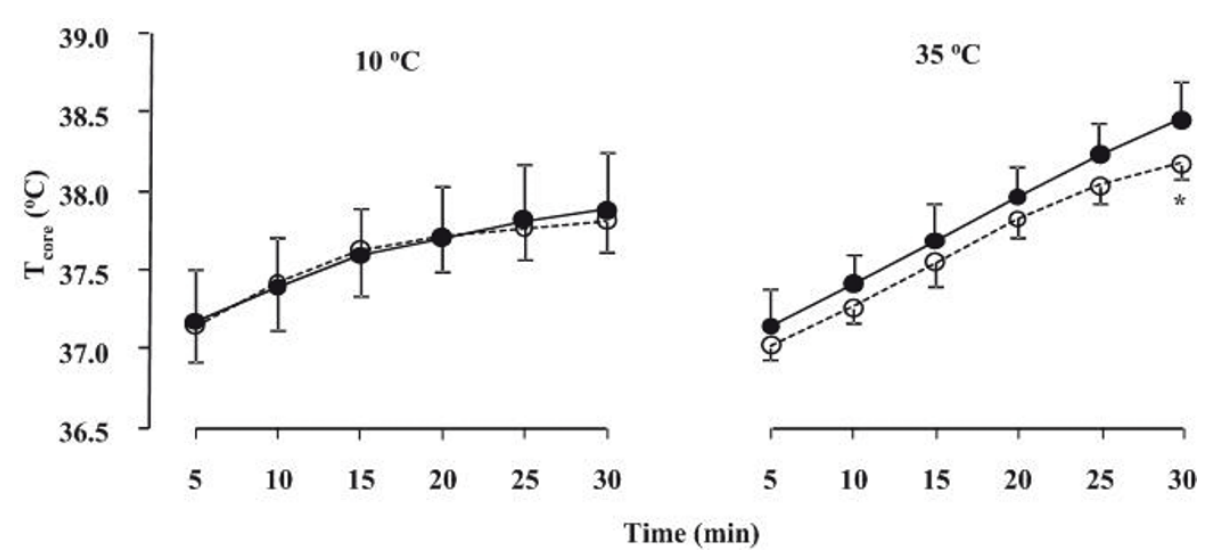

Figure 6 Core temperature $\left(\mathrm{T}_{\text {core }}\right.$ ) during exercise at 10 and $35^{\circ} \mathrm{C}$ before (black circles) and after (white circles) supplementation. Data presented as mean \pm SD. *Significant difference between pre- and post-supplementation.

combination of hydrating agents such as $\mathrm{Cr}$ and Gly that significantly increased body water compartments and reduced cardiovascular (Figure 5) and thermoregulatory (Figure 6) responses during running at $35^{\circ} \mathrm{C}$, had no effect on the oxygen cost of running at $60 \%$ of $\mathrm{V}_{2}$ max. The magnitude of change in $\mathrm{BM}$ following hyperhydration was similar to that previously reported in our laboratory [19] and by Kern et al. (2001). Somewhat smaller differences in body water compartments were observed in the present study compared to the previous investigation by Easton et al. (2007). For example, Easton et al [19] reported an increase of $0.9 \mathrm{~L}$ in TBW and $0.5 \mathrm{~L}$ in ICW after 7 days of supplementation. In the present study TBW and ICW were elevated by 0.7 and $0.3 \mathrm{~L}$ respectively after 7 days of supplementation. These differences could only be attributed to individual responses (i.e., level of "responders" to $\mathrm{Cr}$ supplementation as previously demonstrated) $[13,34]$ as similar protocols were utilised. In the present study, the retained water was dispersed in both the ICW and ECW. Despite the significant increase in BM and body water compartments and consequently improved thermoregulatory responses during exercise, no significant differences in any of the respiratory variables were found between the pre- and post-supplementation exercise trials. Therefore, the finding that a significant increase in BM did not negatively impact on RE of trained runners supports the use of hyperhydration during endurance running when running in hot and humid conditions although confirmatory results are required during faster running speeds typical of sporting competition (i.e., $>85 \% \dot{\mathrm{VO}}_{2} \max$ ).

Temperature and cardiovascular regulation during exercise in the heat do appear to be critically dependent on hydration status $[35,36]$. In the present study, combined $\mathrm{Cr}$ and Gly supplementation induced significant hyperhydration and substantially attenuated the increase in $\mathrm{HR}$ at the end of the $30 \mathrm{~min}$ run at $35^{\circ} \mathrm{C}$ (Figure 5). This attenuation of HR during exercise was of similar magnitude to that previous reported by Easton et al. (2007). As free water in the form of sweat is primarily lost from plasma and since no differences were found in PV changes pre- and post-supplementation despite the increase in TBW, ICW and ECW, it can be suggested that the increase in other water compartments resulted in water moving towards the plasma due to an osmotic gradient. This in turn leaves the PV unaffected. It should be also noted that in order for blood volume to be maintained in conditions of significant thermal stain and therefore sweating, fluid loss is obtained in varying proportions from ECW as well as ICW body water compartments [37]. Furthermore, as loss of body water increases during exercise in the heat as a result of sweating, $\mathrm{T}_{\text {core }}$ also increases [37]. Therefore, increasing body water could potentially result in better maintenance of $\mathrm{T}_{\text {core }}$ during exercise in the heat. Nose et al. [38] reported a strong association between the loss of water in sweat and urine and the decrease in ICW after prolonged exercise in the heat. In the present study, $\mathrm{Cr}$ and Gly induced an increase in ICW and consequently, there was a significant attenuation in the rise of $\mathrm{T}_{\text {core }}$ during exercise in the heat (Figure 6). It is possible that this $\mathrm{Cr}$ - and Gly-induced increase in ICW resulted in an increase of the specific heat capacity of the body [13].

Published studies to date appear to confirm the reduction of $\mathrm{T}_{\text {core }}$ during exercise in the heat following $\mathrm{Cr}$ supplementation $[12,13,19]$. Conversely, when Gly was used alone, ICW was increased without significantly attenuating the rise in $\mathrm{T}_{\text {core }}$ during the exercise period [19]. The effects of Gly ingestion on $\mathrm{T}_{\text {core }}$ and thermoregulation in general during exercise in the heat is equivocal, with several studies reporting a reduction in $\mathrm{T}_{\text {core }}$ 
during exercise [39] and numerous other studies finding no such effect $[16,40]$. In addition, several studies concluded that PV expansion has no effect on thermoregulatory responses or exercise performance during exercise in the heat $[9,41]$. These conflicting results and assertions provide strong support that the thermoregulatory benefits exhibited with Gly ingestion in the present study did not arise from any PV expansion but most likely from an increase heat capacity of the body. Nevertheless, it should also be noted that these thermoregulatory benefits were exerted when Gly was co-ingested with $\mathrm{Cr}$.

Despite the significant increase in TBW and consequently improvement in cardiovascular and thermoregulatory responses during exercise, no differences in $\dot{\mathrm{VO}}_{2}$ were observed during running at $60 \% \dot{\mathrm{VO}}_{2}$ max. Coyle proposed that a reduction in BM induced by dehydration would impact on RE during marathon running by reducing the oxygen cost of running [3]. In contrast, hyperhydration should theoretically increase the oxygen cost of running and therefore RE. However, no such effect was found in the present study. Furthermore, there was no increase in $\dot{\mathrm{VO}}_{2}$ over time during the trial at $10^{\circ} \mathrm{C}$. The latter finding indicates that the subjects were working steadily at the calculated individual running speed corresponding $60 \%$ of $\mathrm{VO}_{2}$ max. It should be noted that this relatively low intensity was chosen in order to ensure that the present data would be comparable with previous studies conducted under similar conditions [12]. Furthermore, the relatively low intensity was chosen as to secure that all subjects could complete the experiment in the heat while it was high enough to observe possible adaptations in cardiopulmonary or thermoregulatory parameters encountered with supplementation. However, $\dot{\mathrm{VO}}_{2}$ was increased during the trial in the heat. This was an expected effect as when exercising in hot environmental conditions, $\mathrm{T}_{\text {core }}$ rises accordingly. It has been shown that with an increase in $\mathrm{T}_{\text {core, }}$ $\dot{\mathrm{VO}}_{2}$ (and therefore RE) also increases [42]. Despite this observation, no discernable difference in $\dot{\mathrm{VO}}_{2}$ between pre- and post-supplementation trials was reported. No other changes in any of the respiratory variables could be observed in the pre- and post-supplementation trials. Similar results have been reported in several other studies using $\mathrm{Cr}$ as the hyperhydrating agent [13] as well as during constant load exercise in the study by Easton et al. (2007) where hyperhydration was induced by $\mathrm{Cr}$ and Gly [19]. The data from the present study suggest that an increase in BM of approximately $1.4 \%$ (average increase in BM in the present study) has no significant effect on $\dot{\mathrm{VO}}_{2}$. Whether such an increase in BM would influence running performance remains to be determined. Furthermore, as HR responses reflect those of $\dot{\mathrm{VO}}_{2}$ [43], the finding that HR during exercise was not significantly different between pre- and post-supplementation trials conducted at $10^{\circ} \mathrm{C}$ is further evidence against any detrimental metabolic effect of the added $\mathrm{BM}$ induced by hyperhydration on RE.

\section{Conclusions}

A hyperhydration strategy that combines $\mathrm{Cr}$ and Gly supplementation for 7 days increased BM and TBW and consequently reduced cardiovascular and thermal strain but did not significantly affect the oxygen cost of running at $60 \%$ of $\dot{\mathrm{VO}}_{2}$ max at $35^{\circ} \mathrm{C}$ in trained runners. The finding that a significant increase in BM did not negatively impact on RE of trained runners, supports the use of effective hyperhydration strategies during endurance running when conditions so dictate (i.e., running in hot and humid conditions). Further studies are necessary however to confirm these findings during faster running speeds reflective of true performance.

\section{Acknowledgements}

The authors acknowledge Oleg Chepelin, Chao Wang and Andreas Anagnostopoulos for their major contribution in the data collection as well as John Wilson for his technical assistance.

\section{Author details}

${ }^{1}$ College of Medicine, Veterinary and Life Sciences, Institute of Cardiovascular and Medical Sciences, University of Glasgow, Glasgow, UK. ²Department of Human Nutrition, Queen Mother Hospital, Tower Block, Glasgow, G3 8SJ, UK.

\section{Authors' contributions}

LYB was the primary author of the manuscript. TP was involved in subject recruitment, data collection and helped to draft the manuscript. DM was involved in data collection and editing the manuscript. YPP conceived of the study, participated in its design and coordination and helped to draft the manuscript. All authors read and approved the final manuscript.

\section{Competing interests}

The authors declare that they have no competing interests.

Received: 19 September 2011 Accepted: 16 December 2011 Published: 16 December 2011

\section{References}

1. Saunders P, Pyne DB, Telford RD, Hawley JA: Factors affecting running economy in trained distance runners. Sports Med 2004, 34:465-485.

2. Bassett DR Jr, Howley ET: Limiting factors for maximum oxygen uptake and determinants of endurance performance. Med Sci Sports Exerc 2000, 32:70-84.

3. Coyle EF: Fluid and fuel intake during exercise. J Sports Sci 2004, 22:39-55.

4. Zouhal H, Groussard C, Minter G, Vincent S, Cretual A, Gratas-Delamarche A, Delamarche $P$, Noakes TD: Inverse relationship between percentage body weight change and finishing time in 643 forty-two-kilometre marathon runners. Br J Sports Med 2010, 45:1101-5.

5. Sawka MN, Burke LM, Eichner ER, Maughan RJ, Montain SJ, Stachenfeld NS: American College of Sports Medicine position stand. Exercise and fluid replacement. Med Sci Sports Exerc 2007, 39:377-390.

6. Nielsen B, Hales JR, Strange S, Christensen NJ, Warberg J, Saltin B: Human circulatory and thermoregulatory adaptations with heat acclimation and exercise in a hot, dry environment. J Physiol 1993, 460:467-485.

7. Ekelund LG: Circulatory and respiratory adaptation during prolonged exercise. Acta Physiol Scand Suppl 1967, 292:1-38. 
8. Fortney SM, Vroman NB, Beckett WS, Permutt S, LaFrance ND: Effect of exercise hemoconcentration and hyperosmolality on exercise responses. J Appl Physiol 1988, 65:519-524.

9. Grant SM, Green HJ, Phillips SM, Sutton JR: Effects of acute expansion of plasma volume on cardiovascular and thermal function during prolonged exercise. Eur J Appl Physiol Occup Physiol 1997, 76:356-362.

10. Magal M, Webster MJ, Sistrunk LE, Whitehead MT, Evans RK, Boyd JC: Comparison of glycerol and water hydration regimens on tennis-related performance. Med Sci Sports Exerc 2003, 35:150-156.

11. Riedesel ML, Allen DY, Peake GT, Al-Qattan K: Hyperhydration with glycerol solutions. J Appl Physiol 1987, 63:2262-2268

12. Kern $M$, Podewils $L$, Vukovich $M, M J$ B: Physiological response to exercise in the heat following creatine supplementation. JEPonline 2001, 4:18-27.

13. Kilduff $L P$, Georgiades E, James N, Minnion RH, Mitchell M, Kingsmore D, Hadjicharlambous M, Pitsiladis YP: The effects of creatine supplementation on cardiovascular, metabolic, and thermoregulatory responses during exercise in the heat in endurance-trained humans. Int I Sport Nutr Exerc Metab 2004, 14:443-460.

14. Green AL, Hultman E, Macdonald IA, Sewell DA, Greenhaff PL: Carbohydrate ingestion augments skeletal muscle creatine accumulation during creatine supplementation in humans. Am J Physiol 1996, 271 E821-826.

15. Steenge GR, Simpson EJ, Greenhaff PL: Protein- and carbohydrate-induced augmentation of whole body creatine retention in humans. J App/ Physiol 2000, 89:1165-1171.

16. Murray R, Eddy DE, Paul GL, Seifert JG, Halaby GA: Physiological responses to glycerol ingestion during exercise. J Appl Physiol 1991, 71:144-149.

17. Nelson JL, Robergs RA: Exploring the potential ergogenic effects of glycerol hyperhydration. Sports Med 2007, 37:981-1000.

18. van Rosendal SP, Osborne MA, Fassett RG, Coombes JS: Guidelines for glycerol use in hyperhydration and rehydration associated with exercise. Sports Med 2010, 40:113-129.

19. Easton C, Turner S, Pitsiladis YP: Creatine and glycerol hyperhydration in trained subjects before exercise in the heat. Int I Sport Nutr Exerc Metab 2007, 17:70-91.

20. Fudge BW, Westerterp KR, Kiplamai FK, Onywera VO, Boit MK, Kayser B, Pitsiladis YP: Evidence of negative energy balance using doubly labelled water in elite Kenyan endurance runners prior to competition. Br J Nutr 2006, 95:59-66.

21. Costill DL: Physiology of marathon running. JAMA 1972, 221:1024-1029.

22. Douglas CG: A method for determining the total respiratory exchange in man. J Physiol 1911, 42:17-18.

23. Beis $L$, Mohammad Y, Easton C, Pitsiladis YP: Failure of glycine-argininealpha-ketoisocaproic acid to improve high-intensity exercise performance in trained cyclists. Int I Sport Nutr Exerc Metab 2011, 21:33-39.

24. Harris RC, Soderlund K, Hultman E: Elevation of creatine in resting and exercised muscle of normal subjects by creatine supplementation. Clin Sci (Lond) 1992, 83:367-374.

25. Gisolfi CV, Summers RW, Schedl HP, Bleiler TL, Oppliger RA: Human intestinal water absorption: direct vs. indirect measurements. Am J Physiol 1990, 258:G216-222.

26. Easton C, Fudge BW, Pitsiladis YP: Rectal, telemetry pill and tympanic membrane thermometry during exercise heat stress. Journal of Thermal Biology 2007, 32:78-86.

27. Convertino VA, Armstrong LE, Coyle EF, Mack GW, Sawka MN, Senay LC Jr, Sherman WM: American College of Sports Medicine position stand. Exercise and fluid replacement. Med Sci Sports Exerc 1996, 28:i-vii.

28. Holland B, Welch AA, Unwin ID, Buss DH, Paul AA, Southgate DAT: The composition of foods. Fifth revised and extended edition of McCance RA, Widdowson ED Goodfellow Egan Phototypesetting Ltd, Cambridge, UK; 1991.

29. Vandenberghe K, Gillis N, Van Leemputte M, Van Hecke P, Vanstapel F, Hespel P: Caffeine counteracts the ergogenic action of muscle creatine loading. J Appl Physiol 1996, 80:452-457.

30. O'Brien C, Young AJ, Sawka MN: Bioelectrical impedance to estimate changes in hydration status. Int I Sports Med 2002, 23:361-366

31. Borg GA: Psychophysical bases of perceived exertion. Med Sci Sports Exerc 1982, 14:377-381.
32. Maughan RJ: A simple, rapid method for the determination of glucose, lactate, pyruvate, alanine, 3-hydroxybutyrate and acetoacetate on a single 20-mul blood sample. Clin Chim Acta 1982, 122:231-240

33. Dill DB, Costill DL: Calculation of percentage changes in volumes of blood, plasma, and red cells in dehydration. J Appl Physiol 1974, 37:247-248.

34. Kilduff LP, Pitsiladis YP, Tasker L, Attwood J, Hyslop P, Dailly A, Dickson I, Grant S: Effects of creatine on body composition and strength gains after 4 weeks of resistance training in previously nonresistance-trained humans. Int J Sport Nutr Exerc Metab 2003, 13:504-520.

35. Gonzalez-Alonso J, Mora-Rodriguez R, Below PR, Coyle EF: Dehydration reduces cardiac output and increases systemic and cutaneous vascular resistance during exercise. J Appl Physiol 1995, 79:1487-1496.

36. Nadel ER, Fortney SM, Wenger CB: Effect of hydration state of circulatory and thermal regulations. J Appl Physiol 1980, 49:715-721.

37. Sawka MN, Montain SJ, Latzka WA: Hydration effects on thermoregulation and performance in the heat. Comp Biochem Physiol A Mol Integr Physiol 2001, 128:679-690

38. Nose H, Mack GW, Shi XR, Nadel ER: Shift in body fluid compartments after dehydration in humans. J Appl Physiol 1988, 65:318-324.

39. Lyons TP, Riedesel ML, Meuli LE, Chick TW: Effects of glycerol-induced hyperhydration prior to exercise in the heat on sweating and core temperature. Med Sci Sports Exerc 1990, 22:477-483.

40. Latzka WA, Sawka MN, Montain SJ, Skrinar GS, Fielding RA, Matott RP, Pandolf KB: Hyperhydration: tolerance and cardiovascular effects during uncompensable exercise-heat stress. J Appl Physiol 1998, 84:1858-1864.

41. Watt MJ, Garnham AP, Febbraio MA, Hargreaves M: Effect of acute plasma volume expansion on thermoregulation and exercise performance in the heat. Med Sci Sports Exerc 2000, 32:958-962.

42. MacDougall JD, Reddan WG, Layton CR, Dempsey JA: Effects of metabolic hyperthermia on performance during heavy prolonged exercise. J Appl Physiol 1974, 36:538-544.

43. Fudge BW, Wilson J, Easton C, Irwin L, Clark J, Haddow O, Kayser B, Pitsiladis YP: Estimation of oxygen uptake during fast running using accelerometry and heart rate. Med Sci Sports Exerc 2007, 39:192-198.

doi:10.1186/1550-2783-8-24

Cite this article as: Beis et al:: The effects of creatine and glycerol hyperhydration on running economy in well trained endurance runners. Journal of the International Society of Sports Nutrition 2011 8:24.

\section{Submit your next manuscript to BioMed Central and take full advantage of:}

- Convenient online submission

- Thorough peer review

- No space constraints or color figure charges

- Immediate publication on acceptance

- Inclusion in PubMed, CAS, Scopus and Google Scholar

- Research which is freely available for redistribution

Submit your manuscript at www.biomedcentral.com/submit
C Biomed Central 